\title{
ГЕНЕЗИС СИСТЕМЫ ГОСУДАРСТВЕННОГО НАЛОГОВОГО АДМИНИСТРИРОВАНИЯ В РОССИИ
}

\begin{abstract}
Аннотация: В статье рассмотрень этапь становления и развития налогового администрирования в России, дана характеристика основным событиям каждого периода. Особое внимание уделено развитию института налогового администрирования в постсоветский период. Доказана взаимосвязь между организационными преобразованиями налоговых органов и трансформацией института налогового администрирования. Обоснованы направления развития налогового администрирования с учетом мировой теории и практики налогообложения.
\end{abstract}

Ключевые слова: Налоги и налогообложение, налог, налоговая система, собираемость, налоговыле органы, администрирование, доход, инспектор, прямые налоги, косвенные налоги

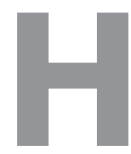

алоговое администрирование представляет собой один из основных элементов управления налоговой системы, способствующих устойчивому функционированию экономики страны. Управление налоговой системой определяется характером и задачами налоговой политики соответствующего этапа развития. В связи с этим исследование проблемы становления и развития налогового администрирования в России позволяет раскрыть его социально-экономическое содержание, особенности современной трансформации, а также эволюционные процессы его становления и современной динамики.

Становление и развитие налогового администрирования осуществлялось одновременно с развитием налоговой системы. Его функционирование неотделимо от развития государства и общества как целостное явление.

Разнообразные методы формирования государственных доходов на протяжении многовековой истории человечества эволюционировали от компенсационных взносов, имеющих разовый характер, к регулярным изъятиям. Первыми регулярными поступлениями были жертвоприношения, как правило, определяемые по долевым ставкам. Исторически выделилась доля обязательных жертв - «десятина», то есть десятая часть доходов. Впоследствии помимо отчислений религиозной направленности возникла так называемая «светская десятина», которая была обоснована необходимостью покрытия государственных расходов. Научные теории, обосновывающие необходимость отчислений в пользу государства, их природу и сущность, появились значительно позже самих доходов в их различных организационных формах. Установление регулярных налогов влекло за собой негативную реакцию плательщиков, которые стремились избежать этого любыми способами. В этих условиях задачей финансовой науки явилось обеспечение теоретической основы для понимания роли налогов в общественной жизни с целью предотвращения уклонения от обложения.

Развитие налоговых отношений, придание им не только обязательного, но и рефлексивного статуса посредством законодательного закрепления и практического воплощения взаимных прав и обязанностей участников, 


\section{Налоги и налогообложение - №3(105) • 2013}

а также упорядочение налоговых норм и правил, их уточнение и конкретизация в законе, предопределило становление и развитие института налогового администрирования.
В России становление и развитие налогового администрирования, на наш взгляд, следует рассматриватьприменительно к четыремэтапам-начиная с конца IX в. и по настоящее время (таблица 1).

Таблица 1

Ретроспектива становления и развития налогового администрирования в России

\begin{tabular}{|c|c|c|c|}
\hline Этапы & Период & Содержание этапа & Характеристика основных событий этапа \\
\hline 1. & $\begin{array}{l}\text { конец IX в. } \\
\text { - первая } \\
\text { половина } \\
\text { XVII в. }\end{array}$ & $\begin{array}{c}\text { Развитие налоговых } \\
\text { отношений. } \\
\text { Становление } \\
\text { налоговой системы }\end{array}$ & $\begin{array}{l}\text { - заложение основ прямого и косвенного } \\
\text { налогообложения; } \\
\text { - замена натуральных платежей денежными; } \\
\text { - с появлением российской государственности } \\
\text { и централизацией власти в конце XV в. } \\
\text { сложились предпосылки для создания } \\
\text { специальных органов, ведающих сбором } \\
\text { налогов в масштабе государства; } \\
\text { - становление системы учета } \\
\text { налогоплательщиков }\end{array}$ \\
\hline 2 . & $\begin{array}{l}\text { вторая } \\
\text { половина } \\
\text { XVII в. - } \\
1916 \text { г. }\end{array}$ & $\begin{array}{c}\text { Формирование } \\
\text { и становление } \\
\text { налогового } \\
\text { администрирования } \\
\text { в Российской } \\
\text { империи }\end{array}$ & $\begin{array}{l}\text { - попытка реализовать принцип } \\
\text { справедливости налогообложения - раскладка } \\
\text { податей на каждого плательщика-тяглеца } \\
\text { производилась совместно правительством и } \\
\text { обществом; } \\
\text { - создано министерство финансов, основной } \\
\text { задачей которого стало управление } \\
\text { государственными доходами и расходами; } \\
\text { - внедрение подоходного налогообложения; } \\
\text { - введение особых местных органов } \\
\text { финансового управления, на которых } \\
\text { возложено было наблюдение за } \\
\text { правильностью распределения прямых } \\
\text { налогов, всестороннее изучение податных сил } \\
\text { населения; } \\
\text { - учреждены должности податных } \\
\text { инспекторов, которые осуществляли контроль } \\
\text { за правильным взиманием налогов, пошлин и } \\
\text { различных сборов на своих участках; } \\
\text { - увеличение собираемости налогов }\end{array}$ \\
\hline
\end{tabular}




\begin{tabular}{|c|c|c|c|}
\hline 3. & $\begin{array}{l}\text { с } 1917 \text { г. по } \\
1991 \text { г. }\end{array}$ & $\begin{array}{c}\text { Разрушение } \\
\text { налоговой системы. } \\
\text { Административные } \\
\text { методы изъятия } \\
\text { прибыли }\end{array}$ & $\begin{array}{l}\text { - прекращение действия налогов в период } \\
\text { военного коммунизма; } \\
\text { - основное звено налоговой системы } \\
\text { - налоговая инспекция - структурное } \\
\text { подразделение районных и городских } \\
\text { финансовых отделов; } \\
\text { - управление налогов и сборов, налоговые } \\
\text { отделы и инспекции были переименованы } \\
\text { соответственно в управления, отделы и } \\
\text { инспекции государственных доходов; } \\
\text { - основная работа по систематическому } \\
\text { контролю за выполнением планов госдоходов, } \\
\text { правильным исчислением и своевременным } \\
\text { поступлением всех платежей в бюджет } \\
\text { возлагалась на городские и районные } \\
\text { инспекции по государственным доходам, } \\
\text { которые входили в структуру районного } \\
\text { (городского) финансового отдела исполкома } \\
\text { соответствующего Совета народных } \\
\text { депутатов }\end{array}$ \\
\hline 4. & $\begin{array}{l}\text { с } 1991 \text { г. - по } \\
\text { настоящее } \\
\text { время }\end{array}$ & $\begin{array}{c}\text { Формирование } \\
\text { налоговой системы } \\
\text { и налогового } \\
\text { администрирования, } \\
\text { отвечающих } \\
\text { рыночным } \\
\text { отношениям }\end{array}$ & $\begin{array}{l}\text { - эволюционное реформирование налоговой } \\
\text { системы; } \\
\text { - возрождение налоговой службы; } \\
\text { - введение законов, регулирующих } \\
\text { функционирование налоговой системы РФ; } \\
\text { - принятие и введение в действие общей и } \\
\text { специальной частей НК РФ; } \\
\text { - внедрение информационных технологий и } \\
\text { функциональная модернизация деятельности } \\
\text { налоговых органов; } \\
\text { - развитие технологий электронного } \\
\text { взаимодействия с налогоплательщиками }\end{array}$ \\
\hline
\end{tabular}

Первый период - это начальный этап становления налоговой системы и налогового администрирования в процессе развития налоговых отношений. Он отличался неразвитостью и случайным характерам установления налогов. В рассматриваемом начальном периоде на Руси были определены виды налогов, которые взимались у населения. Собираемые платежи имели признаки налога - безусловность, безвозврат- ность и индивидуальная безвозмездность взимания. Именно они являются исторической «основой» развития налоговой системы Российского государства.

До становления Московского государства для российской практики налогообложения было характерно наличие множества обязательных податей в пользу князя. Взимание платежей носило не постоянный характер. Единой и сла- 


\section{Налоги и налогообложение - №3(105) • 2013}

женной системы взимания платежей не существовало.

Администрированием большинства прямых налогов занимался Приказ большого прихода. Одновременно с ним обложением населения занимались территориальные приказы. В силу этого налоговая система России в XV - XVII вв. была достаточно сложна и запутана. Вместе с тем, рассматриваемый период характеризуется уже системным подходом к управлению налогообложением Великим князем и формированием единой финансовой системы. Осуществляется проверка финансовой деятельности приказов, проводится анализ приходных и расходных книг.

Прослеживается поэтапная системность администрирования существующих налогов. В этот период были определены органы, отвечающие за поступления в казну причитающихся налоговых платежей. Исходя из проведенных исследований, можно сделать вывод о том, что администрирование существующих платежей началось с формированием государственности Руси и возникновением налоговых взаимосвязей, а также развитием налоговой системы.

Об эффективности налоговой системы в интересах развития экономики в рассматриваемом периоде не могло идти речи. Так как практически финансово-хозяйственные отношения не были развиты. На первоначальном этапе администрирование налоговых платежей носило случайный и бессистемный характер, преследуя только единственную цель по применению мер и мероприятий для удовлетворения потребности княжеского двора.

В дальнейшем администрирование приобретает более организованный и системный характер: определены уполномоченные органы по взысканию налоговых платежей; определен порядок обеспечения платежей в царскую казну; вырабатываются меры принудительного взыскания задолженности.

Особенностью второго периода становления и развития налоговой системы и налогового администрирования было то, что они перешли в новую фазу развития. Актуальность рассмотрения взаимосвязи налоговой системы и налогового администрирования и его эффективности в период экономического развития Российской империи обусловлена богатством исторического опыта налогообложения. Рассмотрение взаимосвязей позволяет не только более глубоко оценить динамику происходящего в данной области в сегодняшние дни и сделать определенные выводы о перспективах развития рассматриваемой проблемы в будущем, но и определить, какие эффективные методы и решения, а также удачные финансовые конструкции могут быть использованы в сегодняшней работе в налоговой сфере.

Проведение налоговой реформы, в результате которой основное бремя налогов было снято с крестьян и переложено на те сословия, которые номинально продолжали числиться в неподатном состоянии, привело к увеличению нагрузки на чиновников Казенных палат. В связи с изменением социального состава плательщиков, введением новых налогов и новых способов их взимания уже вскоре выяснилось, что чиновники не могут справиться с задачей их исчисления и взимания. Усложняющаяся налоговая система настоятельно требовала реформ в области контроля за поступлением налогов, создания соответствующих административных учреждений с целью эффективного администрирования налоговых платежей.

До учреждения податной инспекции надзор со стороны Казенных палат за торговлей и промыслами был весьма слаб. Раз в год чиновники для особых поручений производили их генеральную проверку. Постоянный же 
надзор был возложен на волостных старшин и выборных торговых депутатов, которые в гораздо большей степени заботились о частных интересах торговцев и промышленников, чем о пополнении государственной казны. Уклонение от уплаты торговых пошлин носило массовый характер.

Вместе с тем, существующие налоги и пошлины не были обременительными. За три года (1882-1884 гг.), предшествующих созданию податной инспекции, торговые пошлины составляли 61248 тыс. рублей, а за три года после ее создания (1886-1888 гг.) они возросли до 72243 тыс. рублей ${ }^{1}$.

Без деятельного участия податных инспекций была бы невозможна реформа и администрирование промыслового налога 1898 г. Промысловый налог уплачивался торговыми заведениями и промышленными предприятиями за право ярмарочной торговли. Крупные акционерные предприятия уплачивали дополнительный промысловый налог в форме налога с капитала и процентного сбора с прибыли. Существовал налог на недвижимое имущество. К началу XX в. в России доминировали уже прямые налоги.

Податные инспекции, как исполнительные органы Казенных палат, содействовали водворению более правильных приемов при исчислении и взимании податей и пошлин. Их трудами были собраны разносторонние данные об экономическом положении населения, положенные в основу многих реформ, проведенных в финансовом законодательстве ${ }^{2}$.

Можно сделать вывод о том, что непосредственно чиновнику в лице податного инспектора предписывалась роль «локомотива»в проводимых реформах. Эффективная работа инспекторского состава в конечном результате влияла на собираемость налоговых платежей, уклонение от их уплаты было сведено к минимуму. Результаты исследования свидетельствуют о том, что государственные доходы России XIX в. росли достаточно высокими темпами, в том числе в сравнении с развитыми странами Европы (таблица 2) ${ }^{3}$.

Таблиияа 2 Государственнье доходьл (млн. фунтов стерлингов)

\begin{tabular}{|c|c|c|c|c|c|}
\hline Страна & 1830 г. & 1860 г. & 1881 г. & 1889 г. & Темп роста, \% \\
\hline Англия & 55 & 73 & 83 & 88 & 160 \\
\hline Франция & 41 & 83 & 121 & 121 & 295 \\
\hline Германия & 16 & 32 & 90 & 88,8 & 555 \\
\hline Австро-Венгрия & 18 & 45 & 75 & 74,8 & 410 \\
\hline Россия & 23 & 56 & 80 & 154,7 & 673 \\
\hline
\end{tabular}

${ }^{1}$ Податная инспекция в России (1885-1910 годы). - СПб, 1910. - C. 49.
2 Озеров И. Х. Основы финансовой науки. - Рига: Вып. II. 1923. - С. 102.

3 Янжул И. И. Основные начала финансовой науки / И. И. Янжул. - М. : Старт, 2002. - С. 9. 


\section{Налоги и налогообложение - №3(105) • 2013}

Финансовое положение России перед началом первой мировой войны было довольно устойчивым. По бюджетной росписи на 1914 г. доходы были определены в сумме 3522 млн. рублей, расходы 3303 млн. рублей. В общегосударственных доходах одной из наиболее крупных статей был доход от казенной винной монополии - 935,8 млн. рублей. Казенное имущество и капиталы приносили 805 млн. рублей, среди них наибольшие доходы обеспечивали железная дорога и лесное хозяйство 4 .

Налоги планировались по трем подразделениям: прямые налоги 264,5 млн. рублей, косвенные налоги около 710 млн. рублей и пошлина - более 230 млн. рублей. Среди прямых общегосударственных налогов выделялся промысловый налог - 145,8 млн. рублей с ростом к 1913 г. на 12,2 млн. рублей или на 9,1\%, что говорит о развитии промышленности в России. Поземельный налог, имущественный налог и подати вместе должны были принести казне 83 млн. рублей. Из косвенных налогов почти половину 351,9 млн. рублей - составляли таможенные сборы, 150 млн. рублей - акциз на сахар, 98,4 млн. рублей - акциз на табачные изделия и спички ${ }^{5}$.

Следует отметить, что истинное значение налогов в бюджете дореволюционной России было существенно больше, чем кажется при рассмотрении доходных статей. Например, казенные железные дороги, принося высокие доходы (около 680 млн. рублей), сами же и «съедали» их на свое содержание. Казенная винная монополия учитывается в расходах, поглощая более четверти тех доходов, которые

\footnotetext{
${ }^{4}$ Налоги в дореволюционной России / Библиотека сайта Lib.4i5.ru.2008 : [сайт]. URL: www.Lib.4i5.ru

${ }^{5}$ Налоги в дореволюционной России / Библиотека сайта Lib.4i5.ru.2008 : [сайт]. URL: www.Lib.4i5.ru
}

дает государству. И лишь налоги обеспечивают доходы бюджета государства при минимальных затратах 6 .

Исследование второго этапа развития налоговой системы и налогового администрирования позволяет сделать вывод о том, что налоговая политика государства с четкой организацией налогового администрирования приводит к эффективной налоговой системе, что характеризуется устойчивым финансовым положением государства. Рост эффективности налоговой системы, выразившийся в значительных налоговых поступлениях в казну за счет количественного показателя налогоплательщиков, связан с бурным развитием промышленности в России.

Безусловно, данный рост был обеспечен также за счет применения мер налогового администрирования уполномоченным органом в сфере налогообложения в интересах хозяйствующих субъектов без обременения налогообложения. Улучшение собираемости налогов было осуществлено за счет устойчивого развития российской экономики и эффективной организации работы уполномоченного органа по взысканию платежей.

Третий период характеризуется противоположными тенденциями развития налогообложения, налоговой системы и налогового администрирования при советской власти. Организация работы по налоговому администрированию в рассматриваемом периоде отличалась высокой организованностью со стороны уполномоченных органов.

Вместе с тем, объемы платежей государственных предприятий из прибыли в союзный бюджет и бюджеты республик снижались: 1986 г. - 129,8 млрд. рублей, 1987 г. - 127,4 млрд. рублей, 1988 г. -

\footnotetext{
${ }^{6}$ Налоги в дореволюционной России / Библиотека сайта Lib.4i5.ru.2008 : [сайт]. URL:www. Lib.4i5.ru
} 
119,6 млрд. рублей, 1989 г. - 115,5 млрд. рублей. Параллельно, при росте расходов, масштабы финансового кризиса нарастали. В конце 1991 г. внутренний государственный долг превысил 995 млрд. рублей, внешний долг достиг 47 млрд. инвалютных рублей ${ }^{7}$.

Результаты анализа развития налоговой системы и налогового администрирования в условиях функционирования государственной системы планового распределения финансовых ресурсов показали, что налоговая система выполняла роль аккумулятора части валового внутреннего продукта (ВВП). Функции регулирования развития производства, координации и стимулирования основных направлений его технической модернизации выполняли плановые и снабженческие государственные органы. Присущие мировой налоговой практике и в определенной степени применяемые ранее в инструментарии российской налоговой политики, регулирующая, стимулирующая и социальная функции были полностью замещены механизмами централизованного планирования, государственного снабжения и государственного социального обеспечения.

Налоговая система превратилась в мощный дестабилизирующий фактор развития отечественной экономики: существовавшая практика взимания налоговых платежей в виде отчислений от прибыли и налога с оборота способствовала снижению эффективности функционирования производства, тормозила его научно-техническое развитие, стимулировала процесс разбалансирования товарного рынка. В условиях функционирования государственной системы планового распределения финансовых ресурсов, пред-

\footnotetext{
${ }^{7}$ Федякова Н. И. Исторические аспекты современной налоговой реформы России, начиная с конца 80-х годов XX века : [сайт]. URL: www.bali.ostu.ru.Fediakova.doc.
}

посылки роста эффективности налоговой системы отсутствовали.

Особенность администрирования налоговых платежей заключалась в том, что учет налогоплательщиков осуществлялся путем регистрации финансовыми органами граждан, имевших доходы либо иные объекта налогообложения в СССР.

Четвертыц этап развития связан с кардинальными преобразованиями в политической и экономической жизни России в начале 90-х годов XX в. Интеграция постсоциалистической системы в единый мировой хозяйственный комплекс потребовала создания новой налоговой системы. Однако закладываемые при ее формировании показатели, отвечающие уровню достаточно стабильных иностранных государств, уже с момента создания налоговой системы России не отвечали реальным условиям налогообложения и делали ее неэффективной.

Самой сложной проблемой при разработке новой налоговой системы была необходимость, как минимум, сохранения сложившегося ранее уровня доходов государства, поскольку нельзя было сразу отказаться от финансирования из бюджета целого ряда различных социальны программ. Решение этой задачи усложнялось, с одной стороны, падением производства и сокращением доходов бюджета вследствие уменьшения налоговых поступлений, a c другой стороны - необходимостью компенсации за счет бюджета растущих социальных издержек рыночных преобразований.

Постепенно по мере накопления опыта налогообложения «нерыночные» налоги отменялись, ставки на действующие налоги снижались, вводились новые права и гарантии для налогоплательщиков, смягчались меры ответственности. Однако в результате того, что налоговая система постоянно совершенствовалась, в законодательные акты 


\section{Налоги и налогообложение - №3(105) • 2013}

необходимо было постоянно вносить изменения и дополнения, порой по нескольку раз в год. Как правило, изменения и дополнения имели так называемую «обратную силу», то есть распространяли свое действие на отношения, возникшие с начала года, в котором были приняты данные изменения.

Издавалось огромное количество нормативных документов, разъяснявших порядок применения законов и изменений к ним. В результате налоговая система была невероятно сложной и запутанной. Все эти годы российская налоговая система и применяемые меры налогового администрирования не обладали таким важнейшим качеством, как стабильность. Ситуация несколько улучшилась лишь после принятия вначале первой, а затем и второй частей Налогового кодекса.

Что касается органов, ведущих контроль за своевременностью и полнотой уплаты налоговых платежей в бюджет, то они также неоднократно подвергались реформированию. Созданная в 1991 г. 1Государственная налоговая служба Российской Федерации в 1998 г. была преобразована в Министерство Российской Федерации по налогам и сборам (МНC России), которое в свою очередь в 2004 г. было преобразовано в Федеральную налоговую службу (ФНС России). Вместе с преобразованием структуры налоговых органов изменялись и расширялись выполняемые ими функции.

Организационные преобразования налоговых органов способствовали трансформации института налогового администрирования. Изменения в системе управления налоговыми отношениями сформировали принципиально новые социально значимые институты, ставя перед ними более сложные задачи. На первый план были выдвинуты важнейшие цели социально-эко- номического развития, изменены объекты контроля и его целевые установки.

Государство в лице органов налогового контроля продолжает осуществлять контроль, направленный на проверку законности, правильности и полноты исполнения налоговых обязательств, однако сфера ответственности налоговых администраций перед обществом в новых условиях существенно расширяется. Появляется необходимость оценить качественные характеристики налогового администрирования и выработать конкретные рекомендации по упрощению его процедур для законопослушных налогоплательщиков и переориентации системы контроля на сдерживание налоговых правонарушений и противодействие оппортунистическому поведению.

В последние годы (с 2006 г.) в ФНС России и ее территориальных структурах разрабатывается и внедряется в практику методология налогового администрирования. Она основана на более тщательной подготовке информационной базы, использовании многовариантных проектировок, учитывающих многочисленные факторы, влияющие на процесс налогового администрирования, в том числе оценке влияния на поступления налоговых платежей изменений, вносимых в налоговое законодательство, оценке налогового потенциала. Тем более что с началом автоматизации обработки информации в налоговых инспекциях появилась возможность использования известных статистических методов анализа и прогнозирования налоговых проверок, налоговых поступлений, налоговых правонарушений, налоговых рисков.

Таким образом, четвертый этап развития налогового администрирования в России отличается радикальными полити- 
ческими и экономическими преобразованиями, носит сложный и многоаспектный характер. В связи с чем, считаем возможным разделить его на ряд отдельных временных периодов, характеризующих основные события становления института налогового администрирования в постсоветский период (таблица 3).

Таблица 3

Ретроспектива институцฺионализацฺии налогового администрирования в Российской Федерации

\begin{tabular}{|c|c|c|}
\hline Период & Содержание этапа & Характеристика основных событий этапа \\
\hline 1990-1992 & $\begin{array}{c}\text { Организация инсти- } \\
\text { тута налогового ад- } \\
\text { министрирования }\end{array}$ & $\begin{array}{l}\text { - создание Главной государственной налоговой ин- } \\
\text { спекции в составе Минфина РФ (1990 г.); } \\
\text { - создание Государственной налоговой службы РФ } \\
\text { (1991 г.); } \\
\text { - введение законов, регулирующих функционирование } \\
\text { налоговой системы РФ; } \\
\text { - использование подзаконных актов в качестве фор- } \\
\text { мальных правил налогообложения }\end{array}$ \\
\hline 1993-1997 & $\begin{array}{c}\text { Первичное форми- } \\
\text { рование институ- } \\
\text { циональных норм и } \\
\text { правил }\end{array}$ & $\begin{array}{l}\text { - внедрение информационных технологий и функцио- } \\
\text { нальная модернизация деятельности налоговых орга- } \\
\text { нов в рамках пилотных проектов; } \\
\text { - неупорядоченное развитие регионального и местного } \\
\text { налогообложения, а также внутренних оффшоров; } \\
\text { - активное воздействие судебной практики на совер- } \\
\text { шенствование налоговых правил и условий взимания } \\
\text { налогов; } \\
\text { - директивно-инструктивное регулирование законода- } \\
\text { тельных норм на фоне несовершенства правовой базы; } \\
\text { - активное применение льготных механизмов без учета } \\
\text { их экономической и социальной отдачи }\end{array}$ \\
\hline 1998-2000 & $\begin{array}{l}\text { Кодификация зако- } \\
\text { нодательства и уни- } \\
\text { фикация налогового } \\
\text { администрирования }\end{array}$ & $\begin{array}{l}\text { - создание Министерства по налогам и сборам } \\
\text { (1998 г.); } \\
\text { - принятие и введение в действие общей части НК РФ; } \\
\text { - развитие функциональной специализации админи- } \\
\text { стрирования; } \\
\text { - активизация судебных методов разрешения налого- } \\
\text { вых споров; } \\
\text { - реструктуризация задолженности по налогам }\end{array}$ \\
\hline
\end{tabular}




\begin{tabular}{|c|c|c|}
\hline 2001-2003 & $\begin{array}{c}\text { Введение в действие } \\
\text { специальной части } \\
\text { НК РФ }\end{array}$ & $\begin{array}{l}\text { - снижение числа действующих налогов, упорядоче- } \\
\text { ние применения и сокращение налоговых льгот; } \\
\text { - начало перехода на функциональную структуру дея- } \\
\text { тельности налоговых органов, активизация камераль- } \\
\text { ного контроля; } \\
\text { - внедрение налогового учета; } \\
\text { - использование доктрины «деловой цели» в судебной } \\
\text { практике по налоговым спорам; } \\
\text { - целевое администрирование крупнейших налогопла- } \\
\text { тельщиков }\end{array}$ \\
\hline 2004-2005 & $\begin{array}{l}\text { Оптимизация соста- } \\
\text { ва налогов и сборов }\end{array}$ & $\begin{array}{l}\text { - преобразование МНС РФ в Федеральную налоговую } \\
\text { службу в составе Министерства финансов РФ; } \\
\text { - придание Минфину полномочий в области налогов; } \\
\text { - унификация налоговых процедур в единой автома- } \\
\text { тизированной информационной системе и внедрение } \\
\text { стандартов обслуживания }\end{array}$ \\
\hline 2006-2007 & $\begin{array}{c}\text { Завершение про- } \\
\text { цесса формирования } \\
\text { института }\end{array}$ & $\begin{array}{l}\text { - установление четко регламентированных сроков } \\
\text { и процедур взаимодействия в рамках мероприятий } \\
\text { налогового контроля; } \\
\text { - введение обязательного электронного деклариро- } \\
\text { вания; } \\
\text { - ограничение объема запрашиваемой для контроля } \\
\text { информации при проведении проверки; } \\
\text { - четкое закрепление в законе порядка возмещения } \\
\text { НДС }\end{array}$ \\
\hline $2008-2010$ & $\begin{array}{c}\text { Оптимизация и } \\
\text { упрощение налого- } \\
\text { вого администриро- } \\
\text { вания }\end{array}$ & $\begin{array}{l}\text { - изменение правил зачета излишне уплаченных на- } \\
\text { логов; } \\
\text { - введение процедур досудебного урегулирования на- } \\
\text { логовых споров; } \\
\text { - упрощение камеральных проверок; } \\
\text { - запрет на повторное представление документов на } \\
\text { проверку; } \\
\text { - принятие Концепции планирования выездной нало- } \\
\text { говой проверки и критериев риска совершения налого- } \\
\text { плательщиками налогового правонарушения; } \\
\text { - упрощение налоговых правил и снижение налоговой } \\
\text { нагрузки в рамках антикризисных мер; } \\
\text { - развитие системы предоставления отчетностей по } \\
\text { телекоммуникационным каналам связи. }\end{array}$ \\
\hline
\end{tabular}




\begin{tabular}{|c|c|c|}
\hline $\begin{array}{c}2011-\text { по } \\
\text { настоящее } \\
\text { время }\end{array}$ & $\begin{array}{c}\text { Совершенствование } \\
\text { института налогово- } \\
\text { го администрирова- } \\
\text { ния. Модернизации } \\
\text { налоговых органов } \\
\text { на основе более пол- } \\
\text { ной автоматизации } \\
\text { их деятельности }\end{array}$ & $\begin{array}{l}\text { - максимальное разделение информационной системы } \\
\text { на два блока функций: автоматической обработки ин- } \\
\text { формации (налоговый автомат) и интерактивной работы } \\
\text { пользователей; } \\
\text { - создание централизованной системы ведения ЕГРН } \\
\text { и ЕГРЮЛ, включая единую базу данных сведений } \\
\text { о налогоплательщиках; } \\
\text { - развитие технологий электронного взаимодействия } \\
\text { с налогоплательщиками, включая перестройку серви- } \\
\text { са «Личный кабинет»; } \\
\text { - формирование единой системы мониторинга } \\
\text { и управления деятельностью налоговой службы; } \\
\text { - модернизация инфраструктуры ФНС России. }\end{array}$ \\
\hline
\end{tabular}

Взгляд на эволюцию налогового администрирования позволяет сделать вывод о том, что, в соответствии с изменениями политического и экономического устройства страны, по мере развития государства менялись и способы администрирования налогов и сборов. Совершенство и эффективность системы налогового администрирования в каждый период истории России зависели от степени развития государственного аппарата, социально-экономического уровня развития общества, самого государства и налоговой культуры населения.

Налоговое администрирование является обязательным атрибутом управления государственными финансами, предопределенным объективностью существования налоговых отношений как основного источника государственных доходов. Институт налогового администрирования выступает, с одной стороны, составным элементом организационной структуры уполномоченных контрольных органов, с другой стороны - важнейшей частью налоговой системы. Будучи неотъемлемой частью общественного регулирования, налоговое администрирование обеспечивает практическую реализацию фискальной функции налогов. С другой стороны, как подчеркивает 3. А. Клюкович, контрольные формы взаимодействия налогоплательщиков и органов-администраторов способствуют разрешению конфликта интересов и достижению регулирующих эффектов, изначально предполагаемых при принятии налоговой политики ${ }^{8}$.

В этой связи институт налогового администрирования понимается нами как неотъемлемая часть системы общественноэкономического регулирования со встроенной обратной связью. Он востребован в гражданском обществе для непрерывного мониторинга и анализа состояния социально-экономических процессов, оценки эффективности деятельности экономических субъектов. Действительно работающий институт налогового администрирования, осуществляя профилактические меры и выявляя случаи уклонения от уплаты налогов, может внести значительный вклад в борьбу с коррупцией, мошенничеством, легализацией криминальных денег и другими нарушениями законодательства, активно способствуя тем самым переустройству общества, развитию инновационной экономики и улучшению качества жизни населения.

\footnotetext{
${ }^{8}$ Клюкович 3. А. Налоги и налогообложение / 3. А. Клюкович. - Ростов на Дону : Феникс, 2009. - с. 286-287.
} 


\section{Налоги и налогообложение - №3(105) • 2013}

\section{Библиография:}

1. Клюкович 3. А. Налоги и налогообложение / З. А. Клюкович. - Ростов на Дону: Феникс, 2009. - 344 с.

2. Налоги в дореволюционной России / Библиотека сайта Lib.4i5.ru.2008: [сайт]. URL : www. Lib.4i5.ru.

3. Озеров И. Х. Основы финансовой науки. - Рига: Вып. II. 1923

4. Податная инспекция в России (18851910 годы). - СПб, 1910

5. Федякова Н. И. Исторические аспекты современной налоговой реформы России, начиная с конца 80-х годов XX века : [сайт]. URL : www.bali.ostu. ru.Fediakova.doc.
6. Янжул И. И. Основные начала финансовой науки / И. И. Янжул. - М. : Старт, 2002. -555 с.

\section{References (transliteration):}

1. Klyukovich Z. A. Nalogi i nalogooblozhenie / Z. A. Klyukovich. - Rostov na Donu: Feniks, 2009. - 344 s.

2. Ozerov I. Kh. Osnovy finansovoy nauki. Riga: Vyp. II. 1923

3. Fedyakova N. I. Istoricheskie aspekty sovremennoy nalogovoy reformy Rossii, nachinaya s kontsa $80-\mathrm{kh}$ godov XX veka : [sayt]. URL: www.bali.ostu.ru.Fediakova.doc.

4. Yanzhul I. I. Osnovnye nachala finansovoy nauki / I. I. Yanzhul. - M. : Start, 2002.-555 s. 